\title{
Aproximación al sentido de la palabra musica en las obras de San Agustín*
}

Maximiliano Prada Dussán“"

Para citar este artículo: Prada Dussán, Maximiliano. "Aproximación al sentido de la palabra musica en las obras de San Agustín". Franciscanum 161, Vol. LVI (2014): 17-49.

\section{Resumen}

Con el ánimo de exponer la idea de musica como ciencia -perteneciente al esquema de las artes liberales-, entre los años 386 y 391, Agustín redactó los diálogos De Ordine y De Musica. Por sus sitematicidad, completud y eco en posteriores tradiciones teóricas, estas son las fuentes principales para el estudio de la música en el autor africano. No obstante, también se encuentran referencias a la música a lo largo de su obra. Este artículo revisa el uso que Agustín hizo de la palabra latina musica en sus escritos. Queremos mostrar que tal noción, además de aplicar a la ciencia mencionada, ayuda a la comprensión de: 1. La constitución ontológica del mundo, tanto estática como dinámica; 2. La figura del músico y 3. La teoría organológica y de las formas musicales.

\section{Palabras Clave}

San Agustín, música, ontología, organología, formas musicales.

\footnotetext{
Este escrito es resultado parcial de la tesis desarrollada para optar a título de Doctor en Filosofía por la Universidad Complutense de Madrid.

** Candidato a Doctor en Filosofía por la Universidad Complutense de Madrid. Profesor Asistente de filosofía en la Universidad Pedagógica Nacional de Colombia. Contacto: maxiprada@hotmail.com.
} 


\title{
Approach to meaning of the word musica in the works of St. Agustín
}

\begin{abstract}
Augustine wrote the dialogues De Musica and De ordine in order to explain music as a science. Traditionally, these are the main sources on the topic Augustine's music due to its systematic, extension and relevance among subsequent writers. Nevertheless, the bishop of Hippo referred to music in many other works. This paper reviews in detail the way he used the latin word music on his texts. We will show that these other quotations help us to understand not only the idea of science but also: 1 . the ontological structure of the created world. 2. The idea of 'musicians' and 3. The organological theory and musical forms.
\end{abstract}

\section{Keywords}

St. Augustine, Music, ontology, organology, musical forms.

En el diálogo De Musica (386-391), Agustín define la música como la «ciencia de modular bien» (Musica est scientia bene modulandi) ${ }^{1}$. Esta es la única definición de música que Agustín da a lo largo de sus escritos. Este sentido técnico -como ciencia-se opondría al sentido intuitivo bajo el cual la comprenderíamos hoy: como un arte práctico. A su vez, dicho diálogo es el único texto en el cual el autor explicita el sentido bajo el cual comprende la voz latina musica: explica los elementos que componen la definición y hace un desarrollo sistemático

1 De mus. I.II.2. Para citar las obras de Agustín, en este artículo utilizamos la abreviatura de la obra en latín. La descripción bibliográfica completa de las obras que citemos la incluiremos en la bibliografía al final del texto. El catálogo completo de estas abreviaturas se encuentra en: «Augustinus. It», sitio oficial de la Nueva Biblioteca Agustiniana, consultada en marzo 10, 2013. www.augustinus.it/varie/ tavole/tavola_opere_latino.htm. 
del contenido y procedimientos de dicha ciencia. Por este motivo, ya en el año 1933 Svoboda afirmaba que la estética agustiniana en general, y con mayor razón, su estética musical, debía rastrearse fundamentalmente en las obras tempranas -es decir, las comprendidas entre el 386 y el 391, esto es, desde su conversión al cristianismo hasta el inicio del estudio detallado de las fuentes bíblicas--, recomendación que ha guiado no pocos estudios sobre la música en Agustín.

Aun contando con el extenso examen de la ciencia musical y con la centralidad del De Musica, aparecen referencias a la música en numerosos lugares a lo largo de la obra agustiniana. El propósito de este artículo consiste, entonces, en indagar el sentido bajo el cual Agustín usa la palabra latina musica en sus escritos. El método que seguiremos para ello es inicialmente el rastreo de la aparición de dicha palabra en las obras del autor africano. Ahora bien, se sabe que para Agustín las palabras eran solo signos convencionales que remiten a otras realidades y que a él le interesaba discutir acerca de estas realidades, no sobre las palabras. Por ello, la aproximación a la aparición de la palabra musica es solo el inicio de nuestro análisis. A parte de esto, reconstruiremos sintéticamente el sentido general que la palabra adquiere en cada uno de los contextos mencionados. Esto, a su vez, nos obligará a tener en consideración otros conceptos relacionados, aunque aquella palabra siga siendo nuestro eje articulador.

Por medio de este rastreo y análisis de las apariciones, intentaremos mostrar que, aunque la idea inicial de música como ciencia de modular bien se mantiene en el pensamiento de Agustín, la comprensión que el africano tiene de dicha voz no se restringe a lo contenido en el De Musica, abarcando, si bien de manera no sistemática, los siguientes asuntos: 1. La constitución ontológica del mundo, tanto estática como dinámica; 2. La reconstrucción conceptual de la figura del músico, y 3. La teoría organológica y de las formas musicales. El acercamiento a estos tres asuntos, precedidos de la descripción de las artes liberales y de la idea de ciencia musical, estructuran este artículo. Repararemos 
fundamentalmente en los dos últimos aspectos, pues aunque en los diálogos iniciales de Agustín estos son mencionados, su tratamiento allí es superficial.

Antes de iniciar la exposición propuesta, de manera introductoria haremos un recuento general de las apariciones de la palabra musica en la obra de Agustín ${ }^{2}$. Incluimos dentro de estas apariciones los sustantivos musica-ae, (que se usa para referirse a la ciencia) y musicus, i (que se emplea para referirse al agente, al músico), y el adjetivo musicus-a-um (que se emplea para denotar la idea de sonido e instrumento musical). En total, se encontraron 105 apariciones, distribuidas en 18 obras y 72 parágrafos o lugares específicos. La siguiente tabla reúne lo encontrado:

\begin{tabular}{||c||c||c||c||c||}
\hline Obra & Parágrafo & $\begin{array}{c}\text { Citas por } \\
\text { parágrafo }\end{array}$ & $\begin{array}{c}\text { Citas por } \\
\text { obra }\end{array}$ & Observaciones \\
\hline \hline C. Acad. & I. VII. 21 & 1 & 1 & \\
\hline \hline De ord. & $\begin{array}{c}\text { II. II. 14 } \\
\text { II. II. } 41 \\
\text { II. II. } 49\end{array}$ & $\begin{array}{l}1 \\
1\end{array}$ & 3 & \\
\hline \hline Solil. & II. VI. 12 & 1 & 1 & \\
\hline \hline $\begin{array}{c}\text { De imm. } \\
\text { an. }\end{array}$ & IV. 6 & 1 & 1 & \\
\hline \hline $\begin{array}{c}\text { De mor. } \\
\text { Eccl. Cat. }\end{array}$ & II. XVI. 46 & 1 & 1 & \\
\hline \hline $\begin{array}{c}\text { De mus. } \\
\text { libro 1 }\end{array}$ & $\begin{array}{l}\text { I. I. 1 } \\
2\end{array}$ & 44 & $\begin{array}{c}\text { Se inclulo una } \\
\text { aparición en el } \\
\text { título }\end{array}$ \\
\hline \hline
\end{tabular}

2 Esta búsqueda tiene como referencia la edición latina de los textos de Agustín realizada por los benedictinos de san Mauro, París 1679-1700, reproducida por J. P. Migne, Patrología cursus completus, Serie Latina, (PL) volúmenes 32 a 46, en 1845. De esta edición, usamos la versión latín-español recogida en las Obras Completas de San Agustín, (BAC), tal como se indica en la bibliografía. 


\begin{tabular}{|c|c|c|c|c|}
\hline Obra & Parágrafo & $\begin{array}{l}\text { Citas por } \\
\text { parágrafo }\end{array}$ & $\begin{array}{c}\text { Citas por } \\
\text { obra }\end{array}$ & Observaciones \\
\hline & $\begin{array}{c}\text { I. II. } 2 \\
\text { I. II. } 3 \\
\text { I. III.4 } \\
\text { I. IV.5 } \\
\text { I. IV. } 7 \\
\text { I. IV. } 8 \\
\text { I. V. } 1 \\
\text { I. VI. } 11 \\
\text { I. VI. } 12 \\
\text { I. XIII. } 28 \\
\text { II. I. } 1 \\
\text { II. II. } 2 \\
\text { II. 13.25 } \\
\text { III. I. } 2 \\
\text { III. III. } 5 \\
\text { III. VII. } 16 \\
\text { IV. II. } 3 \\
\text { IV. XVI. } 3 \\
\text { V. XIII. } 28 \\
\text { VI. X. } 25 \\
\text { VI. XIV. } 47\end{array}$ & $\begin{array}{l}6 \\
1 \\
4 \\
2 \\
2 \\
1 \\
1 \\
3 \\
3 \\
1 \\
3 \\
3 \\
1 \\
1 \\
2 \\
1 \\
1 \\
1 \\
1 \\
1 \\
1\end{array}$ & & $\begin{array}{l}\text { Se incluye una } \\
\text { aparición en el } \\
\text { título } \\
\text { Se incluye una } \\
\text { aparición en el } \\
\text { título } \\
\text { Se incluye una } \\
\text { aparición en el } \\
\text { título }\end{array}$ \\
\hline De mag. & I. I. 1 & 1 & 1 & \\
\hline $\begin{array}{l}\text { De doctr. } \\
\text { chr }\end{array}$ & $\begin{array}{l}\text { II. XVI. } 26 \\
\text { II. XVIII. } 28 \\
\text { IV. VII. } 19 \\
\text { IV. XX. } 41\end{array}$ & $\begin{array}{l}4 \\
1 \\
2 \\
1\end{array}$ & 8 & \\
\hline Confess. & IV. XVI. 30 & 1 & 1 & \\
\hline C. Faust. & II. 49 & 1 & 1 & \\
\hline De Trin. & $\begin{array}{l}\text { XII. XIV. } 23 \\
\text { XIV. VII. } 9\end{array}$ & $\begin{array}{l}1 \\
4\end{array}$ & 5 & \\
\hline $\begin{array}{l}\text { De Civ. } \\
\text { Dei. }\end{array}$ & \begin{tabular}{||c} 
II. XXI. 1 \\
XIII. XVII. 2 \\
XVI. II. 3 \\
XVII. XIV \\
XVIII. XII \\
XXII. XXIV.3-4
\end{tabular} & $\begin{array}{l}1 \\
1 \\
1 \\
1 \\
1 \\
1\end{array}$ & 6 & \\
\hline
\end{tabular}




\begin{tabular}{|c|c|c|c|c|}
\hline Obra & Parágrafo & $\begin{array}{l}\text { Citas por } \\
\text { parágrafo }\end{array}$ & $\begin{array}{c}\text { Citas por } \\
\text { obra }\end{array}$ & Observaciones \\
\hline C. Iul. & V. V. 23 & 2 & 2 & \\
\hline Ret. & $\begin{array}{l}\text { I. VI. } \\
\text { I. XI. } 1\end{array}$ & $\begin{array}{l}1 \\
2\end{array}$ & 3 & $\begin{array}{l}\text { Se incluye una } \\
\text { aparición en el } \\
\text { título } \\
\end{array}$ \\
\hline Spec. & $\begin{array}{l}21 \\
23 \\
\end{array}$ & $\begin{array}{l}1 \\
2 \\
\end{array}$ & 3 & \\
\hline Ep. & $\begin{array}{c}\text { 7. II. } 4 \\
\text { 9. } 3 \\
\text { 26. } 3 \\
\text { 32. } 5 \\
\text { 68. } 1 \\
\text { 101. } 3-4 \\
\text { 120. I. } 5 \\
\text { 166. V. } 13\end{array}$ & $\begin{array}{l}1 \\
1 \\
1 \\
1 \\
1 \\
1 \\
1 \\
1\end{array}$ & 8 & $\begin{array}{c}\text { Poema de Licen- } \\
\text { cio } \\
\text { Carta de Paulino } \\
\text { y Teresia a Licen- } \\
\text { cio } \\
\text { Cita Ec. } 22,6\end{array}$ \\
\hline $\begin{array}{l}\text { Enarr. in } \\
\text { Ps. }\end{array}$ & $\begin{array}{c}\text { 32. II. } 5 \\
\text { 32. II. } 8 \\
\text { 41. IX } \\
\text { 42. V } \\
\text { 56. XVI } \\
\text { 80. V } \\
\text { 87. I. } 1 \\
\text { 150. V } \\
\text { 150. VII } \\
\text { 150. VIII } \\
\end{array}$ & $\begin{array}{l}1 \\
2 \\
1 \\
1 \\
1 \\
1 \\
1 \\
1 \\
2 \\
1 \\
\end{array}$ & 12 & \\
\hline Serm. & $\begin{array}{c}65 \text { V. } 6 \\
241 . \text { I. } 1 \\
243 . \text { IV. } 4 \\
360 \text { B }^{4}\end{array}$ & $\begin{array}{l}1 \\
1 \\
1 \\
1\end{array}$ & 4 & \\
\hline 18 & 72 & 105 & 105 & \\
\hline
\end{tabular}

El indicar la aparición de estas palabras latinas es solo la puerta de entrada de nuestro análisis. Examinado el sentido que ellas adquieren en el contexto en el que son incluidas, notamos que la palabra música despliega varios significados:

3 Este Sermo corresponde al número 25 de la colección realizada por François Dolbeau en 1990. 
- Algunas se refieren a la ciencia musical. Se trata, fundamentalmente, de las contenidas en los diálogos De Ordine y De Musica y en C. Acad. I. VII. 21.

- Otras se refieren al diálogo De Musica: Retr. I. VI; I. XI. 1. Ep. 101.

- Otras apariciones subrayan el carácter que tiene la ciencia de acercar a la ontología: Ep. 101 3-4; 166 V. 13; De civ. Dei. II. XXI. 1; XIII. XVII. 2; XXII. XXIV. 3-4; Serm. 243. IV. 4; 360 B. Mostraremos más adelante por qué las ubicamos en un parágrafo independiente.

- Otra serie de apariciones caracterizan la figura del músico: Ep. 7. II. 4; 9. 3; 120 1. V. Confess. IV. XVI. 30. C. Iul. V. V. 23. De civ. Dei. XVII. XIV. De doctr. chr. IV. VII. 19. De imm. an. IV. 6. Spec. 21. De Trin. XIV. VII. 9; XII. XIV. 23. Serm. 65 V. 6; 241. I. 1.

- Otras, se refieren a la música práctica, principalmente a sonidos, instrumentos y formas musicales: Ep. 26 3; 32. 5; 68 1. De civ. Dei. XVI. II. 3; XVIII. XII. De doctr. chr. II. XVI. 26; II. XVIII. 28; IV. XX. 41. De mor. Eccl. Cath. II. XVI. 46; De Mag. I. I. 1. Spec. 23. Enarr. in ps.; 32. II. 5; 32. II. 8; 41. IX; 42. V; 56. XVI; 80. V; 87. I. 1; 150. V; 150. VII; 150. VIII. Serm. 243. IV. 4. C. Faust. XXII. 94. y Solil. II. VI. 12

Es necesario anotar que Agustín, experto en retórica, se refiere a la música también a partir de sinónimos, pronombres o descripciones alternativas, de ahí que un examen completo de este asunto deba tener en cuenta también estas otras maneras de referirse a ella. En nuestro caso, tomamos la palabra música como eje articulador y acudimos a las otras voces para esclarecer el sentido que aquella adquiere ${ }^{4}$.

4 En relación a la voz música se encuentran las siguientes palabras: con la idea ciencia musical: arte (ars), disciplina (disciplina); con la ontología: ritmo (rihythmus), número (numerus), orden (ordo), armonía (en griego: armonía, en ocasiones forma, proportio, ratio), modulación (modulatio), belleza (pulchro, suavitas, specie), poema (Carmen); relacionadas con la idea de músico: cantor (cantator), coro (chorus) y los derivados de instrumentos musicales como citarista, flautista, trompetista; con la de instrumento musical: órgano (organum), instrumento (vasis, instrumentum) y la serie de instrumentos musicales: flauta (tibia), cítara (cithara).... 
Como aproximación primera, no obstante, el rastreo del uso de esta palabra permite afirmar que el africano tuvo este asunto en consideración a lo largo de su obra y que ella adquirió sentidos diversos en momentos distintos ${ }^{5}$. Esto es ya una conclusión que sirve como peldaño estable para continuar la investigación. Iniciemos el análisis de los diversos sentidos de la palabra.

\section{Musica como ciencia ${ }^{6}$}

En los diálogos De Musica y en De Ordine, Agustín expone qué comprende por ciencia musical: como una de las ciencias perteneciente al esquema de las artes liberales. En el camino de encuentro del hombre con Dios, camino que se describe como retorno del alma hacia su origen por vía de la interioridad, estas artes sirven de enlace entre el mundo material (mundo sensible) y el mundo inmaterial (Dios y el alma). Muestran que a través del primero se accede al segundo: per corporalia ad incorporalia. En este sentido, estas artes cumplen una función propedéutica: son una exercitatio animae que prepara al ser humano para el encuentro de las realidades espirituales, esto es, de la filosofía -a la cual, señala el autor africano, no conviene acercarse si antes no se han estudiado las artes- ${ }^{7}$.

Dos características permiten comprender este carácter propedéutico. La primera de ellas consiste en que estas artes se refieren al ejercicio de la razón -o a un movimiento, como lo llama Agustín-. La noción de arte se entiende en este contexto como un despliegue de la razón inmutable ${ }^{8}$, como una organización racional $^{9}$, como un

En este artículo no examinaremos el sentido que adquiere la voz estudiada a la luz de la cronología de las obras, pues consideramos que este asunto requiere un trabajo dedicado solo a ello.

6 La mayor parte de los estudiosos de la música en San Agustín han centrado su atención en analizar los diálogos De ord. y De mus. y, por ende, la mayor parte de la bibliografía secundaria se enmarca dentro de la comprensión de música como ciencia. Aunque son numerosos los títulos que se han dedicado a este asunto, al final de este escrito señalamos algunas de las referencias bibliográficas que pueden orientar este acercamiento.

$7 \quad$ De ord. II.V.15; II.V.17; II. XVIII.47.

8 También denominada razón objetiva o lo verdadero Cfr. De imm. an. VI.10.

9 «¿̇Quién osará decir que la proporción de los números es mudable? ¿̇O que el arte no se funda en esa razón? [...] ¿̇, finalmente, que una cosa es el arte y otra la razón?». De imm. an. IV. 5. 
conjunto de razones: «A veces decimos que el arte es un conjunto de muchas razones, pero entendemos que todas ellas pueden reducirse a una sola ${ }^{10}$. Podría decirse que el conjunto de estas razones configuran un arte, en cuyo caso este adquiere el sentido de ciencia y disciplina. Solo a partir del vínculo con la razón universal, alcanza, a su vez, un terreno práctico, en donde el arte se comprendería como la razón en su capacidad organizativa. En este contexto, resulta ser sinónimo de conceptos como precepto, orden, ley, método. Así, las artes son un movimiento que se alcanza meramente por vía de la razón, movimiento que permite descubrir principios ordenadores. En el caso de la música, ordenadores de los números en el tiempo.

El movimiento propio de la razón consiste en separar y enlazar, en el análisis y la síntesis. Y solo es posible analizar y separar aquello que «parece uno y no lo es o no es tan uno como parece» ${ }^{11}$. Aquello que se presenta en unidad, pero cuya unidad no descansa en ello mismo. Esto es, su objeto es el descubrimiento de lo permanente y su campo de observación es aquella realidad en la cual se hace presente lo estable y lo inestable: el mundo cambiante. Por ello, estas artes son el punto intermedio ${ }^{12}$ de un camino que inicia en la percepción de lo corpóreo y que desemboca en el estudio mismo de las realidades espirituales.

La segunda característica de la función propedéutica consiste en que las artes liberales, en tanto movimiento del alma, conllevan un movimiento ético. A este carácter ético apunta directamente la noción de Liberal, así: algunos conocimientos están orientados hacia el mantenimiento de la vida, mientras que otros buscan liberar al hombre, en el sentido -neoplatónico- de conducirlo hacia lo inteligible, de un retorno del alma hacia el origen. Dicho giro lo denomina Agustín

10 De imm an. IV. 5. El carácter racional de las artes hace que su conocimiento no provenga de ninguna suerte de adivinación. A esto se refiere cuando Agustín incluye la voz musica en C. Acad. I. VII. 21.

11 De ord. XVIII. 48.

12 Cf. José Morán, El hombre frente a Dios: el proceso humano de la ascensión a Dios según San Agustín (Valladolid: Estudio Agustiniano, 1963), 88. 
conversión (conversio), en oposición a la aversión (aversio). Así, el estudio de las artes liberales conduce al ser humano a la conversión ${ }^{13}$.

Tal como lo comprende Agustín, dicha liberación podría darse por dos vías (las palabras y los números), las cuales, organizadas en razones y secuencias fundan las siete disciplinas liberales (tres literarias y cuatro numéricas) ${ }^{14}$. Dentro de cada una de ellas, a su vez, el camino se organiza en una serie de preguntas distribuidas dialécticamente que, en la medida en que son planteadas y se intentan responder, ayudan al descubrimiento de las realidades eternas. En tanto el alma las descubra, se afirma que se eleva, tanto en el sentido de descubrimiento como de conversión, «de modo que tanto mejor saben vivir y con tanta mayor elevación cuanto más perfectamente la contempla [se refiere a la ley por medio de la cual Dios ordena el mundo] con su inteligencia y la guarda con su vida» ${ }^{15}$. En la concepción de Agustín no es compatible la contemplación racional de realidades inmateriales junto a prácticas de deseo del mundo material, pues entiende que una vez se contempla lo que tiene mayor valor no es posible vivir bajo reglas que no provengan de ello. En la vía inversa, las prácticas que reniegan del mundo material son también preparación para el descubrimiento de lo inmaterial, en el sentido en que disponen el alma para ello.

Estos dos elementos, el epistemológico y el ético, pues, caracterizan las artes liberales y muestran su valor propedéutico. En este marco de comprensión se incluye la música. La idea que Agustín tiene de ella la sintetiza en la definición: "Musica est scientia bene modulandi (Música es la ciencia del modular bien)» ${ }^{16}$. ción a la estética de San Agustín (Madrid: Instituto Luis Vives de Filosofía, 1945), 105.

De ord. II. VIII. 25.

De mus. I.II.2. Esta definición fue una de las más afortunadas en la teoría musical de la edad media. Agustín la conoció directamente de Varrón, pero era ya característica entre los tratadistas musicales. Este tratado fue el más valioso tratado de música de su tiempo. Cf. Alonso Ortega, «Introducción al De Musica», en Obras completas de san Agustín, tomo XXXIX (Madrid: B.A.C. 1988), 73; Enrico Fubini, La estética musical desde la Antigüedad hasta el siglo XX (Madrid: Alianza, 2007), 87. 
Agustín analiza uno a uno los componentes de la definición: qué significa modulandi, qué bene y qué scientia ${ }^{17}$. Por modulandi entiende ordenar un movimiento (un ritmo, un tiempo). El orden o la disposición en el movimiento puede darse de dos maneras: una que apunta a la consecución de un fin distinto a sí mismo y aquella en el cual el fin es él mismo. El caso de la música es el segundo, se trata de ordenar un movimiento de modo que él mismo se convierta en fin en sí mismo: en el caso de los sonidos bellos, se buscaría que en ellos se haga presente la belleza, como fin en sí misma. Según esto, la ciencia musical analizaría el tipo de ordenación que haría de la práctica musical un objeto bello, no el que haría de ella un objeto útil.

La organización que mienta la voz modulandi es interna a la obra musical, esto es, regula los movimientos internos a la composición. La partícula bene se añade al notarse la necesidad de una cierta modulación externa, esto es, atendiendo a la conveniencia de hacer sonar una composición dentro de un contexto específico ${ }^{18}$. Finalmente, el carácter de scientia se refiere a que ella es un conocimiento de tipo teorético, no un conocimiento práctico, que persigue descubrir los principios de la modulación, interna y externa, pues los principios son racionales y se alcanzan por vía de la razón. Es un arte en el sentido ya expuesto ${ }^{19}$.

El diálogo de Agustín centra su atención en explicitar en qué consiste la modulación -sus principios, mecanismos y cómo estos aplican a los sonidos- y en qué sentido estos cumplen la función de hacer retornar al alma hacia el uno. A esto dedica el autor africano los libros II al VI del mentado diálogo. Podemos esquematizar este desarrollo en los siguientes pasos:

17 La primera parte del libro primero del De Musica Agustín la dedica al análisis de la definición. Cf. De mus. I. II. 3 - VI. 12.

18 Este tipo de conveniencia no fue desarrollada sistemáticamente por Agustín. Solo algunas alusiones en obras posteriores hacen referencia a ella, como en Spec., 23.

19 Ellsmere y La Croix afirman que el De Musica es el primer testimonio histórico de la primera separación entre belleza y obra de arte, toda vez que se renuncia a la imitación como norma de la belleza. Cf. P. K. Ellsmere y Richard R. la Croix, edit., Augustine on music: an interdisciplinary collection of essays (New York: The Edwin Mellen Press, 1988), 1-17. 
1. De la teoría métrica a la matemática: a. reducción de figuras métricas (de palabras) a figuras rítmicas (a números) y de las combinaciones entre dichas figuras a proporciones matemáticas y b. descubrimiento de que la belleza radica en las proporciones de igualdad, que, a su turno, tienen origen en la unidad.

2. Descubrimiento de la presencia de números y proporciones en el alma humana.

3. Hallazgo del principio trascendente de unidad dentro del alma, como principio que permite percibir y comprender los entes como unidad y como objetos estéticos, capaces de belleza.

Este camino ilustra el cometido de las artes liberales. En el paso 1 se muestra el desprendimiento del mundo material y la elevación desde los sonidos hacia los números; en el paso 2, el camino de interioridad que es necesario para el descubrimiento del origen de los principios de la belleza; en el paso 3, el encuentro con la unidad, principio trascendente que opera como condición de posibilidad de la constitución de cada ente en cuanto es, y de la experiencia estética en cuanto posibilidad de percibir -recordar, producir, juzgar-cada objeto como uno y como bello. En la dirección contraria -del principio de unidad a la materia- este principio funciona como regulador de los sonidos en orden a que estos alcancen belleza. $\mathrm{La}$ comprensión de la unidad por sí misma sería asunto de la filosofía, no de la ciencia musical.

Hagamos dos precisiones sobre el desarrollo de la ciencia musical en relación a la definición. La definición postula el análisis de la modulación del movimiento. Aunque el diálogo De Musica centre su atención en el análisis del ritmo, el propósito de Agustín consistía en abarcar también el otro aspecto concerniente a la música: el melos, esto es, pretendía también desarrollar una teoría que explicara los principios por medio de los cuales se definen las alturas de los sonidos y las relaciones interválicas -aspecto que, según la definición, también lo incluiría pues son también «movimientos»-. 
En lugar de la métrica, dicha teoría tomaría por punto de partida el análisis de instrumentos de viento o de cuerdas $^{20}$. Agustín no desarrolla esta teoría del melos, no obstante, algunas alusiones en escritos posteriores muestran el camino que quizás esta pudo haber tomado: en síntesis, se trataría de una explicación acerca de cómo las proporciones matemáticas definen las alturas y las relaciones interválicas de los sonidos ${ }^{21}$.

La segunda precisión tiene que ver con el carácter de ciencia, frente a la práctica musical. A partir de la concepción asumida, Agustín diferencia y toma partido entre música teórica-docta, o ciencia musical-y música de uso o práctica. Usando los términos que emplea en De Doctrina Christiana, sería la diferencia entre la música del sabio y la del lujurioso ${ }^{22}$. Esta última se refiere al hecho acústico y a su producción; asuntos que dentro del esquema ontológico neoplatónico se referían al trato con la materialidad de la música. Merece la pena indicar que, dentro de los círculos intelectuales neoplatónicos, esta gozaba de mala reputación al ser considerada símbolo del hedonismo, motivadora de orgías y de sensualidad y carecía de sustento teórico consistente ${ }^{23}$. Por lo mismo, quienes se dedicaban a interpretar instrumentos o al canto eran tenidos en menor estima que quienes se dedicaban a la ciencia ${ }^{24}$. La dedicación a la ciencia, por su parte, reflejaba el primado de la razón sobre los instintos y la sensualidad, en tanto mostraba que la razón, por medio de la modulación matemática, regía el mundo material. Al inclinarse por la ciencia, Agustín mostraba su adhesión a los postulados básicos

20 Los aspectos técnico-musicales provenientes de la antigüedad pueden ser consultados gracias a los documentos originales y de comentadores que hasta hoy han llegado. Los tratados de Aristoxeno y Ptolomeo suelen considerarse los de mayor importancia desde un punto de vista técnico, equiparables posteriormente al tratado de Boecio. Reese presenta una lista de cerca de 20 textos con los que se cuenta hoy. Para este asunto, véase Gustave Reese, La música en la Edad Media (Madrid: Alianza Música, 1989), 39-41.

21 Este otro aspecto que abarcaría la música lo menciona en De Doctr. Chr. II. XVI. 26.

22 Ibíd., IV. VII. 19.

23 Cf. Gino Stefani, L'etica musicale di S. Agostino (Roma: Pontificia Universidad Lateranense, 1969), 5.

24 «Cuando vemos que los elefantes, los osos y algunas otras especies de animales se mueven al ritmo del canto, y que hasta las aves mismas se deleitan en sus propias voces [...] ¿̇no habrá que compararlos (a los hombres que, sin tener ciencia, escuchan gustosamente) a estos animales?». De mus. I.IV.5. 
de los círculos intelectuales de su tiempo y asumía los postulados teóricos usados por ellos para su tratamiento.

En suma, musica es aquí comprendida como ciencia, un conocimiento, un conjunto de razones acerca de la modulación del tiempo o del movimiento bello, de manera que quien alcanza dicho conocimiento se dispone al encuentro con realidades espirituales. Decíamos inicialmente que esta comprensión de la palabra se hizo central en el pensamiento agustiniano, pero también en los estudios posteriores ${ }^{25}$, de modo que esta se ha convertido en la significación que tradicionalmente ha dominado el campo de la crítica.

\section{La música y la ontología}

La idea general de las artes liberales presenta a la música como un conocimiento por medio del cual los seres humanos acceden al mundo espiritual. Siguiendo la estela del Timeo y del libro bíblico de la Sabiduría (en el cual Agustín lee que todo fue hecho según número, medida y peso), en relación directa con la música Agustín señala que en dicho mundo se hace presente directamente la estructura estable bajo la cual Dios ordenó lo creado: la constitución ontológica numérica. Se trata de un mundo que muestra la armonía, el orden, lo bello; es una suerte de cosmos, en el sentido de orden.

Siendo armónica la estructura ontológica del mundo, la música es también la ciencia que permite conocer dicha estructura ${ }^{26}$. En efecto,

Aunque el libro de Varrón Sobre las disciplinas, en el cual se encuentra esta definición, se perdió durante la Edad Media, la definición se mantuvo viva en los relatos de Censorio, Agustín y tangencialmente en Marciano Capella. La Edad Media, no obstante, cita a Agustín como su autor. Bowen proporciona una lista de autores medievales y renacentistas que la citaron, bien sea directamente o por medio de otras fuentes: son pocas las referencias a esta definición entre los siglos v y xiII. En el siglo VI, Casiodoro e Isidoro la mencionan, en el siglo IX Aureliano de Reome, en el x aparece en el Scolica Enchiriadis, en el xi en el Liber Argumentorum y en el xiI en Jerome de Moravia. La definición se hizo común sobre todo en los siglos XIV al XVI. En el xIV Pedro de Santo Domingo la cita, en el xv, Juan de Muris, Adam de Fulda y Franchinus Gafurio. En el siglo xvi la tienen en cuenta Juan Cocleaus, Martin Agricola, Heinrich Glarean, Francisco de Salinas y Tomas Morley. Cf. William Bowen, «St. Augustine in medieval and Renaissance musical science», Richard R. la Croix, ed., op. cit., 30-32. Ver también Alonso Ortega, «Introducción al De Musica», op. cit., 73 Ep. 166, V. 3. 
este arte muestra cómo la creación temporal -en el caso de la música, los sonidos-, puede ser ordenada por los números de modo que en su movimiento muestre belleza. Posteriormente, Agustín aplica este principio a otros dominios de la creación temporal: el ser humano, la naturaleza, la sociedad, la historia. Estos otros elementos también están constituidos por el orden y en su desarrollo serían capaces de belleza. La mathesis musical analizada en el De Musica se convierte en mathesis universal, asunto que poco a poco será objeto ya no de las artes liberales sino de la filosofía. Acerquémonos a estas nuevas cuestiones.

A diferencia de su procedimiento frente a la gramática, Agustín no desarrolla una reducción sistemática a números de estos otros ámbitos mencionados, aunque mantiene la idea de que el número es el lenguaje ontológico de estas realidades y que las relaciones entre los elementos creados se rigen por el orden que, al igual que en el caso de la regulación de los sonidos bellos, persigue la igualdad y busca la unidad $^{27}$. En lugar de una descripción numérica, se hacen relevantes los principios de antítesis y sucesión como condiciones ontológicas que posibilitan la emergencia del orden bello en lo creado ${ }^{28}$. Sostenemos que la antítesis podría entenderse como un desarrollo en el orden ontológico general, del principio aplicado a la música, según el cual la belleza puede emerger solamente de sonidos distintos. La sucesión, por su parte, puede serlo del principio según el cual cada sonido musical debe ser finito y debe dejar de existir para que pueda aparecer otro sonido, de modo que pueda hablarse de obra musical.

Como lo deja ver Uña Juárez ${ }^{29}$, el orden configura la realidad cruzando dos coordenadas: una primera coordenada que habla de la creación en su condición estática (ser) y dinámica (devenir) y una segunda coordenada que habla del mundo natural y del mundo

27 Cf. De mus. VI. XVII. 57-58.

28 Sobre la antítesis véase De civ. Dei. XI. 18. Sobre la sucesión, Ep. 166, 13. Una síntesis de estos principios se encuentra en: De nat. b. VIII. Agustín Uña Juárez, Cántico del universo: la estética de San Agustín (Madrid: s.d.e., 2000), 117 ss., muestra que Agustín poco a poco irá dando relevancia al carácter dinámico de la creación. La estética, en este sentido, es una estética de lo temporal. Bajo este supuesto, las categorías que resaltan la belleza son las de antítesis y sucesión. 
humano. En el cruce de estas dos se vislumbra un ordenamiento del mundo humano en su condición (conditio) y en su administración (administratio) así como de la naturaleza (creación y evolución) ${ }^{30}$. Detengámonos en mostrar sintéticamente esta idea.

Tanto el cuerpo como el alma humanas están regidos por el orden numérico. Si el avance del conocimiento lo permitiera, señala Agustín, nos daríamos cuenta de que cada parte del cuerpo ha sido creada por Dios bajo este principio, de modo tal que en él todo responde a utilidad o a belleza ${ }^{31}$. El desarrollo posterior del cuerpo llevaría a una configuración en la que este perdería la corruptibilidad y necesidad, y llegaría a ser un cuerpo hermoso.

En cuanto al alma, al seguir el orden el ser humano se comprende como parte finita, mortal -no eterna- e intermedia -racional a la vez que animal- dentro de la estructura ontológica neoplatónica ${ }^{32}$. Agustín considera que comprender esta idea, permite a cada cual entender su lugar en dicha organización: le permite ver que no es él el creador, le permite situarse como creación. Así, en el ámbito ético-antropológico, la proporción ontológica que rige el mundo se decanta finalmente por una doble relación: se traduce en la necesidad de una relación ordenada de la parte (el ser humano) con el todo (Dios) y de parte a parte (relación entre seres humanos y de seres humanos con otros entes creados) $)^{33}$. Al situarse como parte, el ser humano encuentra que bajo esta condición puede alcanzar belleza ${ }^{34}$.

30 Cf. De vera rel. XXII. 43.

31 De civ. Dei. XXII. XXIV 3-5; Serm. 243. IV. 4.

32 En De Ord. II.XIX.50. Agustín define al hombre como animal racional mortal.

33 Cfr. De mus. VI. XIV. 46. Gersh señala que en el esquema relacional, de procedencia aristotélica, se definen tres tipos de relación: la relación entre contrarios, la relación de la parte con el todo y la relación de los contrarios juntos frente al todo. En la descripción que hacemos de Agustín, en este punto solo tiene en cuenta las relaciones primera y segunda. Cf. Stephen Gersh, Concord in discourse: harmonics and semiotics in late classical and early medieval platonism (Berlin: Mouton de Gruyer, 1996), 122.

34 Este hecho lo explica Agustín por medio de una metáfora musical: «Si durante el tiempo en que dentro de un poema suenan las sílabas, tuviesen ellas simultáneamente vida y capacidad perceptiva, de ninguna manera les causará placer la armonía y belleza de la obra continuada, al no poder contemplarla y aprobarla toda entera. Ya que fue configurada y llevada a su acabamiento gracias a cada una de esas sílabas que iban pasando». De mus. VI. XIV. 46. 
Desde ya se deja ver que solo el hombre que se reconoce en su finitud y que se concibe como parte es capaz de hacer de su vida una obra bella. Esta comprensión de sí mismo es denominada por Agustín, humildad. Pero el ser humilde es solo un primer paso dentro de la construcción de una vida bella, aunque es ya la conquista de una meta. Haría falta aún el desarrollo constante de la virtud, el mantenerse bajo dicha comprensión y condición. Le espera al hombre, entonces, la práctica y conocimiento de una vida bienaventurada; lo que en el diálogo Sobre la Cantidad del Alma denomina crecimiento del alma. Por un camino de siete pasos ${ }^{35}$, el alma humana crece hasta alcanzar la perfección de hacerse uno en el cuerpo místico de Cristo ${ }^{36}$.

La estructura ordenada alcanzaría también los ámbitos de la naturaleza y de la historia. Agustín desarrolla una visión estética de la naturaleza según la cual las cosas del mundo son bellas por el hecho mismo de ser y están ordenadas de modo que las inferiores sirvan a las superiores. Así, la sucesión de las cosas terrestres, subordinadas a las celestes, forman en su conjunto el cántico del universo (carmini universitatis) ${ }^{37}$.

Lo mismo sucede con la historia. La Ciudad de Dios, su fundación (carácter estático) ${ }^{38}$ y desarrollo (carácter dinámico), operan como un poema sinfónico, como el Carmen pulcherrimum ${ }^{39}$, orientado por la belleza: los dos amores, antitéticos entre sí, quedan subsumidos dentro de la tensión o direccionamiento histórico hacia la configuración en unidad del cuerpo místico de Cristo ${ }^{40}$. Esto hace de la historia una sucesión bella y esperanzadora en medio de la confusión generada por la caída del imperio romano.

\footnotetext{
35 Cf. De quant. an. XXXIII-XXXVI.

36 Cf. De Trin. XIV. XVIII. 24.

37 Cf. De mus. VI. XI. 29; VI. XVII. 57-58.

38 Cf. De civ. Dei. II. XXI. 1.

39 Cf. De civ. Dei. XI. 18

40 Gersh señala que en la historia de la ciudad de Dios se puede ver el esquema relacional en sus tres tipos de relación. Cf. Stephen Gersh, op. cit., 124. Esta visión es resaltada por Uña Juárez en su estudio. Cf. Agustín, Uña Juárez, op. cit., 132.
} 
Las descripciones acerca del ser humano, la naturaleza y la historia son solo algunos de los ámbitos en los que Agustín hace visible la ontología común de lo creado ${ }^{41}$. Bajo este supuesto, entonces, la música termina convirtiéndose en lugar privilegiado de entrada a la estructura ontológica general. Como señala en la Ep. 166, a Jerónimo y en la 101, a Memorio, para entender que el cosmos está gobernado por los números, Dios dio la música a los hombres ${ }^{42}$. En este sentido, la palabra musica estaría relacionada más con el orden ontológico, que con el análisis mismo de la modulación o la producción de sonidos bellos.

Cerremos este asunto señalando que las alusiones que hemos traído a colación muestran que la práctica musical y los demás dominios analizados comparten una misma ontología. En virtud de este hecho, Agustín despliega una serie de analogías que comparan uno y otro ámbito con el fin de mostrar y explicar cómo opera dicho mundo ontológico estable. No sobra insistir en que en este caso tales analogías se fundan en que ambos lados de la comparación comparten una misma característica ontológica. Otro sería el análisis que habría que hacer de estas analogías desde el punto de vista de una teoría del signo y del lenguaje, asunto que no entra en nuestra consideración por el momento.

\section{La música y los músicos}

La voz musica también la emplea Agustín en relación a los agentes que entran en contacto con la ciencia musical. En términos generales, quien se relaciona con la ciencia musical es llamado músico (musicus), esto es, quien examina los principios de la modulación y sigue el camino racional; no obstante, en ocasiones el concepto puede describir también a quien domina un instrumento siempre y cuando esto sea

41 También se encuentra, por ejemplo, en torno a la constitución del cuerpo humano. Cf. De civ.Dei. XXII. XXIV. 4.

42 Cf. Ep. 166, 13; 101. 3. Además de los apartes ya citados, en muchos otros lugares de su obra Agustín muestra esta relación entre la música y otros aspectos del mundo creado. Véase por ejemplo: De vera rel. XXII. 43; De Gen. C. Man. V. XXI. 32. 
fruto de su encuentro con los principios de belleza, tal como el alma domina al cuerpo ${ }^{43}$. Por su parte, quien interpreta un instrumento sin tener el arte dentro de sí, suele ser denominado en acuerdo al instrumento: citarista, flautista, cantor ${ }^{44}$. Dentro de este último grupo, Agustín centra su atención en la figura del cantor, de modo tal que suele contraponer este -como representante del grupo de instrumentos-a la figura del músico. La tradición crítica ha recogido esta tendencia bajo el asunto de distinguir entre músico y cantor ${ }^{45}$.

Dentro del esquema descrito en el parágrafo anterior, el músico es aquel que tiene por perspectiva el mundo inmaterial. ¿̇e qué forma lo hace? Trascendiendo el nivel del mero placer que origina la música práctica y el del virtuosismo técnico, para acceder al plano de los principios que determinan la belleza musical, plano únicamente alcanzable por el uso de la razón. En este contexto, el músico es aquel que desarrolla este discurso, aquel que dedica sus esfuerzos a desvelar los principios de la modulación. En tanto se encamina en este proyecto, el músico se aparta poco a poco de la materia de la música, es decir, de los sonidos, y se encuentra con los números que gobiernan la modulación. Así, pues, el músico es aquel que logra escapar de las ataduras del mundo material, mundo necesariamente cambiante, y se instala en el mundo abstracto estable y verdadero.

¿Qué lugar ocupa aquel que se dedica a la música práctica o de uso dentro de esta concepción agustiniana? Aunque la exigencia a los músicos prácticos sería que previamente conocieran los principios de la modulación y que centraran su atención en estos, no en los sonidos,

43 La primera denominación se hace presente en el De Musica. Para la segunda véase, por ejemplo, Serm. 65. VI; Serm. 241 II. 2.

44 Tendencia habitual en los tratados de la época. Véase por ejemplo Mario Severino Boecio, Sobre el fundamento de la música (Madrid: Gredos, 2009), I, 34.

45 El trabajo de Solange Corbin sigue siendo referencia fundamental para entender la distinción entre músico y cantor en Agustín. En su artículo, «Musica spéculative et cantus pratique: le rôle de saint Augustine dans la transmission des sciences musicales», Cahiers de Civilisation médiévale. Xe et XII ${ }^{\mathrm{e}}$ siècle 5, (1962): 1-12, la autora muestra que la distinción está presente en autores anteriores a Agustín, específicamente en Clemente de Alejandría y Orígenes. Propone la hipótesis de una posible superación de la dicotomía en Agustín. De alguna manera, nuestra referencia sigue esta hipótesis. 
en el contexto del De Musica Agustín sospecha de la posibilidad de que aquellos que ejecutan un instrumento -citaristas, flautistas o cantores- pudieran estar guiados por los principios racionales que descubren las artes liberales ${ }^{46}$. Esto lo señala a partir de una observación inicial sobre las prácticas de los instrumentistas: la ejecución práctica requiere el ejercicio y adiestramiento corporal, el afianzamiento de patrones de movimiento cifrados en la memoria y el despliegue de cierto gusto musical sensible, al punto que bien puede decirse que flautistas, citaristas y cantores están siempre imbuidos dentro del que considera mundo material de la música; su mismo ejercicio les impide desprenderse de allí ${ }^{47}$.

Aunque la sospecha de Agustín se alce inicialmente en un terreno empírico, en el sentido en que dice no haber encontrado en su tiempo el primer histrión o intérprete que haya alcanzado ya el mundo espiritual, el análisis del diálogo lleva a concluir que la separación trasciende el plano histórico y se instala en los órdenes epistemológico y ético. Iniciemos en el asunto epistemológico. En el caso particular del De Musica, esta crítica se levanta sobre el análisis de la relación entre los intérpretes y su público. Agustín afirma que los intérpretes están movidos directamente por la aprobación de sus oyentes, no por la belleza del arte; parecen medir su virtud a partir de los aplausos que son capaces de conseguir en cada espectáculo. Ante esto, pregunta: «quien canta o aprende a cantar, no por ninguna otra razón sino para ser alabado del pueblo o de cualquier hombre en general, ¿̇no juzga que es mejor la alabanza que el canto?» ${ }^{48}$. A partir de allí, pues, concluye que los cantores no conocen la ciencia. En efecto, en caso de conocerla, no buscarían la alabanza del público, en tanto la ciencia musical constituye un valor mayor que la aceptación social.

Cf. De mus. I. IV. 5; I. IV. 8.

Cf. Ep. 9. III.

De mus. I. VI. 12. 
Con base en lo anterior, no duda en comparar a los cantores con los animales ${ }^{49}$. Ni unos ni otros logran desprenderse del mundo material: los animales en virtud del lugar que ocupan dentro de la estructura ontológica neoplatónica, los segundos por su renuncia al despliegue de la racionalidad. Ambos, en suma, producirían sonidos bellos en virtud de la capacidad imitativa ${ }^{50}$, pero no en virtud de la racionalidad. Empleando los términos del De immortalitate animae, no tienen el arte en su alma ${ }^{51}$, solo lo imitan. Con todo, Agustín se suma a aquella tradición que afirma que antes que hacer, es mejor saber qué se hace. Esto es, el ideal humano se encuentra en el músico, no en el cantor.

Pero, decíamos, a Agustín interesa tanto el ámbito epistemológico de conocimiento de otra realidad, como el ético de adhesión a esto otro. El descubrimiento del mundo inmaterial por vía de la razón es solo el primer paso, en tanto el descubrimiento racional de otra realidad no garantiza que el hombre se instale, viva dentro de este otro mundo ${ }^{52}$. Para ello, haría falta un compromiso del alma entera, esto es, una adhesión, una conversión del corazón. Así pues, el descubrimiento racional requiere ser superado por el acercamiento amoroso a este mundo, lo cual constituye un paso más dentro del camino humano ${ }^{53}$. ¿Cómo son interpretados el músico y el cantor dentro de esta perspectiva del amor a lo no material?

49 En el desarrollo del primer libro del De mus. es frecuente esta comparación, en especial en los parágrafos I. IV. 5. Hasta I.VI.12. Dentro de ellas se destacan citas como esta: «En consecuencia, o tendrás que decir que las picazas, los papagayos y los cuervos son animales racionales, o atrevidamente llamaste arte la imitación. Pues vemos que estas aves cantan y emiten muchos sonidos de una cierta manera parecida a la del hombre, y que no lo hacen sino en virtud de la imitación». De mus. I.IV. 6.

50 Es necesario tener en cuenta que el sentido de imitación aquí no es el mismo que en la definición del arte en la tradición platónica. Aquí imitación está referido al mundo material, no al inmaterial; esto quiere decir que en este contexto la imitación se remite a la ejecución, ejercitación corporal para producir cierto sonido, no a algún tipo de intuición ideal de formas. Sería, en términos platónicos, la imitación de la apariencia, no la imitación del modelo.

51 De imm. an.. IV. 6. Al tener el arte en el alma, los músicos producen sonidos bellos en los instrumentos musicales. Cf. Serm. 65. VI. y 241 II. 2.

52 «ट̇Crees tú que merece menos consideración el hecho de que en esta alma no se produzca al mismo tiempo la adhesión a las realidades eternas, una vez que en ella está ya el conocimiento de que debe adherirse a ellas?». De mus. VI. XIII. 38.

53 Es esto lo que algunos críticos llaman una segunda conversión. La primera corresponde al descubrimiento racional del mundo inmaterial, paso que comenzó a dar Agustín tras la lectura del Hortensio, de Cicerón. La segunda, al compromiso amoroso con esta otra realidad, paso que dio tras la escena del huerto, según relata en las Confesiones. 
Después de que el músico ha encontrado los principios de la modulación por medio del camino racional, tiene que vérselas con su adhesión amorosa hacia ellos (hacia el Uno, hacia Dios). Se encuentra, entonces, en la encrucijada de amarse a sí mismo, en lo que Agustín denomina la actitud soberbia, o de amar a Dios y al prójimo, en lo que constituiría la actitud humilde; actitud propia del más humano entre los humanos ${ }^{54}$.

La situación del cantor es otra, dado que este no inició el camino racional que posibilitó al músico enfrentarse a la encrucijada amorosa posterior. En los términos del De Musica, el cantor no es más sino aquel que, sin haber descubierto otra posibilidad ético-epistemológica, continúa amando las realidades inferiores: sigue amando el mundo material de los sonidos y sigue amándose a sí mismo por medio de la adulación del público que lo aplaude. Usando la terminología de este diálogo, diremos que el placer sensible y la adulación que otros proporcionan son aún su tesoro, de ahí que los siga amando. No ha encontrado aún un tesoro mayor. Sinteticemos la distinción de esta manera: los cantores aman realidades inferiores y no han logrado concebir algo distinto a ellas; los músicos quizás aún las amen, pero han logrado concebir otra posibilidad de su amor, esto muestra que su alma se dirige hacia otra realidad distinta a la del cantor.

Cerremos este asunto diciendo que si bien bajo la consideración de la diferencia entre el camino científico del músico frente al conocimiento práctico del cantor, Agustín podría admitir la posibilidad de un cantormúsico, llegados a este punto la distinción se hace radical. En efecto, si el cantor está movido por el aplauso del público y por el deleite de los sonidos, esto es signo de que su alma no está dirigida hacia realidades inmateriales. Uno y otro camino resultan ser contrarios.

54 De mus. VI. XIV. 45. Después del descubrimiento racional del mundo inmaterial el músico guarda en su memoria lo encontrado. De Trin. XII. XIV. 23; XIV. VII. 9. Para adherirse al mundo verdadero, debe superar las imágenes que podrían surgir en su fantasía una vez hace consciente los conocimientos musicales que ha depositado en la memoria. La razón ayuda en la labor de distinguir lo verdadero de los fantasmas. Cf. Ep. 7. II. 4. 
No obstante, la valoración de uno y otro cambiará en textos posteriores. En sus primeros diálogos, Agustín centra su atención en el músico, en aras de caracterizar lo que recordaría al músico-filósofo platónico. Habría que esperar hasta escritos posteriores para volver a encontrar desarrollos sobre el cantor. En escritos como la Ciudad de Dios y los Comentarios a los Salmos, Agustín vuelve a referirse a ellos, aunque no de modo sistemático como lo había hecho en los diálogos iniciales y bajo valoraciones y presupuestos distintos. Estos otros presupuestos son ya no el esquema de las artes liberales, sino el énfasis en el encuentro con la realidad espiritual a través de la mediación simbólica.

En el caso concreto de los cantores, Agustín introduce un esquema teórico que antes no había tenido en cuenta para referirse a la música, este es, la idea según la cual las obras musicales en las ceremonias litúrgicas son signos, en sentido lingüístico (como signum), no ontológico (como vestigia) ${ }^{55}$. En cuanto tales, ya no son meramente objetos materiales (res) que producen o no producen placer y que deben ser trascendidos racionalmente, sino que son llamados, advertencias, invitaciones a considerar (en el sentido de creer, esperar y amar) algo distinto a ellos: en concreto, la música práctica es un signo de las realidades eternas de la Ciudad de Dios.

El cantor, en este contexto, en lugar de ser concebido como alguien que ama el mundo inferior y que en virtud de ello solo es capaz de emitir sonidos llamando al deleite, es en esta nueva perspectiva quien invita a considerar la realidad espiritual por medio de su aparición material en signos, esto es, en obras musicales ${ }^{56}$. Bajo esta comprensión el cantor deja de ser comparado con animales. En lugar de ser un simple promotor del placer sensual, es ahora un intérprete, un anuncio, es quien expresa una fe a la cual previamente se ha adherido en su interior, fe que puede ser compartida por una comunidad.

55 Para rastrear la idea de la música práctica como signo, pueden consultarse las siguientes referencias agustinianas: De Doctr. Chr. II. III. 4; Enarr. in PS., 87. 1; 130. 1; 149. 7; Spec. 21.

56 Alusiones al coro se encuentran en: Enarr. in Ps. 87. 1; 122. 2; 123. 1-3; 130. 1-3; 149. 7; De civ. Dei II.XXI.1; Confess. IX. VII. 16. 
No sería necesario, entonces, el camino racional desplegado en las artes liberales para que a partir de los sonidos bellos el ser humano se encuentre con la verdad, haría falta comprender los signos en el interior, asunto que tiene que ver más con las experiencias de enseñanza, tradición y autoridad.

Así, aunque en sus inicios Agustín hiciera una defensa radical del camino de los músicos -científicos- frente al del cantor, esta valoración parece dar un vuelco con el paso de los años. Ya hemos visto cómo los cantores son reinterpretados a la luz de su capacidad simbólica. Ahora el camino racional es puesto en cuestión como vía privilegiada al encuentro con lo inmaterial, cediendo su lugar a los signos por medio de los cuales se hace presente la verdad espiritual -dentro de los cuales la figura de Cristo, mediador, se hace central-.

Dentro de tal giro cobran sentido los comentarios que hizo sobre las artes liberales en su libro de las Retractaciones, escritas entre los años 426 y 427, apenas unos años antes de su muerte. Refiriéndose a los diálogos filosóficos señala: «En estos libros me desagrada (...) el que he dado mucha importancia a las artes liberales, que ignoran muchas personas santas, y algunas que las conocen no son santas» ${ }^{57}$. Esto no quiere decir que Agustín proponga que haya que desechar la razón y las ciencias en el camino hacia lo espiritual. En su lugar, indica que estas ya no ocupan el lugar privilegiado que ocupaban antes. Como señala Harrison, la razón cede el puesto a la fe, esperanza y caridad. Por nuestra parte, añadimos que las ciencias ceden el lugar a los signos ${ }^{58}$.

En este sentido, el desagrado frente a las artes liberales no se debe a que ellas estén erradas por sí mismas o a que ellas conduzcan al error; se opone a su valor independiente, esto es, el valor que puedan tener si estas son tomadas por fuera del marco epistemológico y ético cristiano que ve en Dios y en Cristo la verdad y el camino que fundamentan la vida bienaventurada. Así, lo que Agustín propone 
no es desechar tales saberes -de hecho, en De Doctrina Christiana reconoce el valor que tienen para la formación del cristiano- sino servirse de ellos en una revaloración: ahora deben servir a la formación cristiana: deben ser un apoyo en el estudio de la biblia, de la doctrina y la historia del cristianismo ${ }^{59}$.

El camino de encuentro con lo inmaterial propuesto por el neoplatonismo cede su puesto a los principios bíblicos de ascenso. En el caso concreto de la distinción entre músicos y cantores, esto desemboca en que los músicos son ahora tales en virtud de su fe y de la expresión de ella por medio de signos, y no por el dominio de la ciencia racional musical. En la búsqueda del modelo para los músicos, Pitágoras, como descubridor de la ciencia musical, cede el puesto al rey David, como compositor y cantor de piezas musicales de alabanza a $\operatorname{Dios}^{60}$.

\section{Música en relación al sonido, a los instrumentos y a las formas musicales}

Aunque Agustín comprenda la música como una ciencia, en ocasiones también usó este concepto para referirse a sonidos, organología y formas musicales. El énfasis que los estudiosos han puesto en el diálogo De Musica ha hecho que este apartado del discurso musical haya quedado relegado a un segundo plano, viendo en él solamente una aplicación práctica de la ciencia musical o una serie de alusiones inconexas y carentes de estructura sólida. Por nuestra parte consideramos que este es un capítulo que merece ser atendido en el pensamiento agustiniano; ello obligaría a dirigir la mirada a otra serie de obras, en especial, a los Comentarios a los Salmos.

Iniciemos señalando que el empleo de la voz musica en referencia al campo práctico se da tanto al inicio del camino de la ciencia musical, como en su punto de retorno, ya sea de retorno de la ciencia o del camino de la fe. Como inicio, se encuentra la apelación al sonido: esta suele 
hacerse para diferenciar el sonido mismo y las palabras que pueden acompañarlo, por ejemplo en una composición vocal ${ }^{61}$. Esto lo hace para diferenciar la constitución numérica de la estructura significativa. Tanto la voz humana, como la de los animales y los sonidos de los instrumentos guardarían una constitución numérica independiente de su significado.

Como retorno, la alusión a la práctica constituye inicialmente la vía de regreso al mundo material después de haber comprendido los principios espirituales de la belleza por medio de la ciencia musical. En efecto, una vez el artista capta los principios, vuelve al mundo material para darle a este orden y armonía; para hacer de las sucesiones de sonidos, sucesiones bellas. En este sentido, el discurso de la organología y de las formas musicales haría parte también del campo de conocimiento que atañe a la ciencia musical, toda vez que sería un capítulo acerca de cómo el arte organiza el mundo, ya no por vía de la creación divina, sino de la creación humana ${ }^{62}$. Quizás haría parte de aquel discurso sobre el melos que no alcanzó a desarrollar. Su conocimiento, al igual que se hizo sobre el ritmo en las composiciones vocales, tendería a mostrar cómo en la morfología de los instrumentos y en su afinación se debe hacer presente el orden numérico.

Los instrumentos musicales en los que Agustín centra su organología son la cítara, el salterio, la flauta y el tímpano, aunque también los trata en conjunto, como organum ${ }^{63}$. En la mayoría de los casos, Agustín se detiene a especificar la forma del instrumento y cómo este ha sido construido. Un ejemplo de cómo los instrumentos están gobernados por el número lo constituye el salterio, cuyo número de cuerdas (diez) hace que este instrumento simbolice los diez mandamientos. Por el contrario, no es usual que Agustín se refiera al tipo de sonido que producen los instrumentos. Tampoco se detiene a especificar los tipos de sonidos que produce la voz humana. Al referirse a ella, más bien lo hace para

61 Cf. Solil. II. VI. 12.

62 Cf. Ennar. in Psal. 150. 8.

63 El conjunto de los Comentarios a los Salmos sería la obra en la cual Agustín despliega, aunque no sistemáticamente, su organología. Dentro de ellos rescatamos especialmente los comentarios a los salmos: 32, 41, 42, 56, 80, 87, 122, 123, 130, 149, 150. También se encuentra en De mor. Eccl. cath. II. XVI. 46. 
especificar formas y composiciones musicales: canto de los salmos, himnos, canto del aleluya y formación coral ${ }^{64}$. En todo caso, bien sea la organología o las formas vocales, al estar conformados por el orden trascendente, todos ellos son también una ventana hacia la ontología ${ }^{65}$.

Ahora bien, aunque Agustín comprenda que formas e instrumentos musicales guardan proporciones numéricas y que en virtud de estas son capaces de reflejar la belleza, el discurso predominante sobre ellos es de carácter simbólico o alegórico ${ }^{66}$. En este sentido, la proporción que guardan frente al mundo espiritual se establece no por relaciones numéricas sino en virtud de que ellos son signos de realidades espirituales que no son alcanzables por vía de la razón sola, sino por una experiencia de revelación, de fe. Así, por ejemplo, las flautas simbolizan el anuncio; el salterio y la cítara, las obras; el coro, la unidad; el canto de himnos y salmos simbolizan la adhesión interna de los fieles a la fe cristiana.

¿Siguen siendo música estas descripciones? Como señalábamos, las indicaciones dadas en el De Musica y en otras referencias acerca de la ciencia musical, afirman que la capacidad significativa no formaría parte del discurso de la ciencia musical. No obstante, Agustín parece conservar dichas indicaciones significativas dentro de la palabra musica, quizás porque a la base del simbolismo se encontraría una ontología común. Así, conserva la voz musica para referirse a instrumentos (vas, organum, instrumentum), aunque con ella haga alusión a la significación más que a la constitución ontológica numérica ${ }^{67}$. Con ello, lo que tiene en mente Agustín es que Cristo -y no el uno abstracto- es la suprema belleza. En conse-

64 Sobre formas de composición vocal pueden verse los comentarios a los salmos: 87, 121, 122 o 123. En la Ep. 32 hace referencia a los modos musicales, de los cuales afirma haber sido aficionado en su juventud. Puede estar refiriéndose a los descritos en el De mus. Cf. Ep. 32, V. Fuera del ámbito musical, Agustín hace referencia a que los discursos también guardan un despliegue numérico ordenado. Cf. De doctr. chr. IV. XX. 41.

65 Cf. De Doctr. chr., II. XVI. 26.; De doctr. chr., II. XVIII. 28; Serm. 243. IV. 4.

66 En este sentido, mostramos nuestro desacuerdo con el análisis de Laura Folli, quien ve en las Enarrationes in Psalm un despliegue auténtico de la ontología neoplatónica y deja casi sin mencionar la teoría del signo empleada por Agustín para referirse allí a la música. Cf. Laura Folli, «Canticum cordis: la música e l'interiorità nelle Enarrationes in psalmos di Agostino», ed., Latterio Mauri, La música nel pensiero medievale (Ravenna: Longo Editore Ravenna, 1999).

De civ. Dei. XVI. II. 3. 
cuencia, las obras de arte se hacen bellas no solo en cuanto sigan patrones numéricos, sino en cuanto se acerquen a él, lo reflejen o imiten; esto es, en cuanto guarden proporción -significativa- a él. En este sentido, el discurso organológico y de las formas musicales en su capacidad significativa, tendrían las puertas abiertas dentro del marco general de un discurso sobre la música.

Van Deusen ha señalado, no sin razón, que la organología agustiniana no constituye un discurso suficientemente sólido de modo tal que su seguimiento aproxime al lector a hacerse una idea del estado de evolución del campo en el siglo v; esto en virtud de que las descripciones sobre instrumentos ceden el paso rápidamente a consideraciones éticas. En este orden de ideas, remite a los lectores a la organología de Casiodoro para alcanzar este cometido. Por nuestra parte, consideramos que el interés de Agustín no consiste en elaborar un discurso meramente organológico; su intención parece ser mostrar que los instrumentos musicales -y las formasson también una ventana para comprender y adherirse al mundo espiritual, bien sea a través de la descripción numérica o de la simbólica. Este carácter de anuncio, de advocación, domina sus alusiones a estos objetos. De allí que no pueda exigirse al africano dicho discurso musicológico.

\section{Conclusiones}

En este artículo hemos intentado mostrar que la palabra música en la obra agustiniana sufre modificaciones con respecto al sentido en el que la empleó en los diálogos De Ordine y De Musica. Dichas modificaciones amplían la comprensión de la palabra, abarcando dominios que incluso negó bajo la primera comprensión. Dentro de ellos se destaca el hecho de considerar las prácticas musicales como posibilitadoras de acceso al mundo espiritual sin la mediación racional, la idea de cantor como agente que en su práctica misma refleja dicho mundo y un discurso sobre instrumentos y formas musicales en su capacidad significativa. 
Teniendo en cuenta dichos cambios, se concluye que el estudio de lo que Agustín entiende por musica debe trascender el análisis exclusivo de los diálogos tempranos, debe abarcar obras posteriores y debe incluir otros esquemas teóricos distintos a los desplegados allí: en lugar de la estructura racional, se alza la estructura de fe, esperanza y caridad como acceso a la belleza; en lugar de la estructura matemática se alza la estructura significativa; en lugar de las ciencias, los signos.

\section{Bibliografía}

Agustin, San. C. acad.: Contra Académicos. T. III. Edición de Victorino Capánaga. Madrid: Biblioteca de Autores Cristianos, 1951. . C. Faus.: Réplica a Fausto, el maniqueo. T. xxxi. Edición de Pío de Luis. Madrid: Biblioteca de Autores Cristianos, 1993. . C. Iul.: Réplica a Juliano. T. xxxv. Introducción de Argimiro Turrado. Traducción y notas por Teodoro Calvo Madrid y Luis Arias Álvarez. Madrid: Biblioteca de Autores Cristianos, 1984.

. Confess. Confesiones. Versión de Ángel Custodio Vega. Madrid: Biblioteca de Autores Cristianos, 1955.

. De civ. Dei. La Ciudad de Dios. Edición de Santos Santamaría del Río, Miguel Fuertes Lanero, Victorino Capánaga y Teodoro Calvo Madrid. Madrid: Biblioteca de Autores Cristianos, 2009.

. De doctr. chr. La Doctrina Cristiana. T. xv. Edición de Balbino Martín Pérez. Madrid: Biblioteca de Autores Cristianos, 1969.

. De Gen. C. Man. Comentario al génesis en réplica a los maniqueos. T. Xv. Edición de Balbino Martín Pérez. Madrid: Biblioteca de Autores Cristianos, 1969.

. De imm. an. La inmortalidad del alma. T. xxxix. Edición de Lope Cilleruelo et ál. Madrid: Biblioteca de Autores Cristianos, 1988.

. De mag. El maestro. T. III. Traducción de Eusebio Cuevas. Madrid: Biblioteca de Autores Cristianos, 1951. 
Agustin, San. De mor. Eccl. Cath. De las costumbres de la Iglesia católica y de las costumbres de los maniqueos. T. IV. Versión de Victorino Capánaga et ál. Madrid: Biblioteca de Autores Cristianos, 1975.

. De mus. La música. T. xxxix. Edición de Lope Cilleruelo et ál. Madrid: Biblioteca de Autores Cristianos, 1988.

. De nat. b. La naturaleza del bien. T. iII. Traducción de Eusebio Cuevas. Madrid: Biblioteca de Autores Cristianos, 1951.

. De ord. El orden. T. I. Versión de Victorino Capánaga. Madrid: Biblioteca de Autores Cristianos, 1946.

. De quant. an. La dimensión del alma. T. III. Traducción de Eusebio Cuevas. Madrid: Biblioteca de Autores Cristianos, 1951.

. De trin. La trinidad T. v. Versión de Luis Arias. Madrid: Biblioteca de Autores Cristianos, 2006.

. De vera rel. La verdadera religión. T. Iv. Versión de Victorino Capánaga et ál. Madrid: Biblioteca de Autores Cristianos, 1975.

. Ennar. in. ps. Comentarios a los salmos I. T. xix. Edición de Balbino Martín Pérez. Comentario al salmo 32. Madrid: Biblioteca de Autores Cristianos, 1964.

. Ennar. in. ps. Comentarios a los salmos II. T. xx. Edición de Balbino Martín Pérez. Comentario a los salmos 41, 42 y 56. Madrid: Biblioteca de Autores Cristianos, 1965.

. Ennar. in. ps. Comentarios a los salmos III. T. xxi. Edición de Balbino Martín Pérez. Comentario a los salmos 80 y 87. Madrid: Biblioteca de Autores Cristianos, 1966.

. Ennar. in. ps. Comentarios a los salmos IV. T. Xxir. Edición de Balbino Martín Pérez. Comentario a los salmos 122, 123, 130, 149 y 150. Madrid: Biblioteca de Autores Cristianos, 1967.

. Ep. Cartas I. T. VIII. Edición de Lope Cilleruelo. Cartas 7, 9, 26, 32, 68, 101 y 123. Madrid: Biblioteca de Autores Cristianos, 1986.

. Ep. Cartas II. T. XI. Edición de Lope Cilleruelo. Carta 166. Madrid: Biblioteca de Autores Cristianos, 1953. 
Agustin, San. Retr. Retractaciones. T. xL. Traducción de Teodoro Calvo Madrid. Madrid: Biblioteca de Autores Cristianos, 1995.

. Serm. Sermones II. T. x. Edición de Lope Cilleruelo et. ál. Sermón 65. Madrid: Biblioteca de Autores Cristianos, 1983. . Serm. Sermones IV. T. xxiv. Edición de Pío de Luis. Sermones 241, 243. Madrid: Biblioteca de Autores Cristianos, 2005.

. Serm. Sermones VI. T. xxvi. Edición de Pío de Luis. Sermón 360. Madrid: Biblioteca de Autores Cristianos, 1985.

. Solil. Soliloquio. T. I. Edición de Victorino Capánaga. Madrid: Biblioteca de Autores Cristianos, 1946.

. Spec. El espejo de la sagrada escritura. T. Xxvir. Edición de Miguel Marcos Casquero. Madrid: Biblioteca de Autores Cristianos, 1991.

Bettetini, Maria. Introduzione a Agostino. Bari: Laterza, 1999.

. «Musica tra cielo e terra: lettura del De Musca di Agostino D'Ipponna». En La música nel pensiero medievale, 103-122. Editado por Latterio Mauri. Ravenna: Longo Editore, 2001. . «Stato della questione e bibliografía ragionata sul dialogo De Musica di Sant'Agostino (1940-1900)». Revista di filosofía neo-scolastica 83, (1991): 430-469.

Boecio, Mario Severino. Sobre el fundamento de la música. Madrid: Gredos, 2009.

Bowen, William. «St. Augustine in medieval and Renaissance musical science». En Augustine on music: an interdisciplinary collection of essays, editado por Richard R. la Croix, 29-52. New York: The Edwin Mellen Press, 1988.

Corbin, Solange. «Musica spéculative et cantus pratique: le rôle de saint Augustine dans la transmission des sciences musicales». Cahiers de Civilisation médiévale. $X^{e}$ et XII ${ }^{e}$ siècle 5, (1962): 1-12.

De Bruyne, Edgar. Historia de la Estética II: la antigüedad cristiana. La Edad Media. Madrid: Biblioteca de Autores Cristianos, 1963. 
Folli, Laura. «Canticum cordis: la música e l'interiorità nelle Enarrationes in psalmos di Agostino». En La música nel pensiero medievale, editado por Latterio Mauri, 177-194. Ravenna: Longo Editore Ravenna, 2001.

Fubini, Enrico. La estética musical desde la Antigüedad hasta el siglo xx. Madrid: Alianza, 2007.

Gersh, Stephen. Concord in discourse: harmonics and semiotics in late classical and early medieval platonism. Berlin: Mouton de Gruyer, 1996.

La Croix, Richard R. edit. Augustine on music: an interdisciplinary collection of essays. New York: The Edwin Mellen Press, 1988.

Harrison, Carol. Beauty and revelation in the thought of Saint Augustine. Oxford: Clarendon Press, 1992.

McKinnon, James William. «Musical Instruments in Medieval Psalm commentaries and Psalters». Journal of the American Musicological Society 1, Vol. 21, (1968): 3-20.

Montero Honorato, María del Pilar. «La música en san Agustín». Studium Ovetense 16, (1988): 155-178.

Morán, José. El hombre frente a Dios: el proceso humano de la ascensión a Dios según San Agustín. Valladolid: Estudio Agustiniano, 1963.

Nueva Biblioteca Agustiniana. «Augustinus. It». Consultada en marzo 10, 2013. www.augustinus.it/varie/tavole/tavola_opere_latino.htm.

O'Connell, Robert J. Art and the Christian intelligence in St. Augustine. Oxford: Basil Blackwell, 1978.

Ortega, Alonso. «Introducción al De Musica». En Obras completas de san Agustín, tomo xxxix. Madrid: Biblioteca de Autores Cristianos, 1988.

Otaola González, Paloma. El De Musica de san Agustín y la tradición pitagórico platónica. Valladolid: Estudio Agustiniano, 2005. 
Perl, Carl Johann y Kriegsman, Alan. «Augustine and Music: On the Occasion of the $1600^{\text {th }}$ anniversary of the Saint». The Musical Quarterly 4, Vol. 41 (1955): 496-510.

Reese, Gustave. La música en la Edad Media. Madrid: Alianza música, 1989.

Rey Altuna, Luis. ¿Qué es lo bello? Introducción a la estética de San Agustín. Madrid: Instituto Luis Vives de Filosofía, 1945. . «San Agustín y la música». Augustinus 5, Vol. 18 (1960): 191-206.

Sobrevilla, David. «La estética agustiniana». Logos: Revista de Filosofía 7 (1979): 7-51.

Stefani, Gino. L'etica musicale di S. Agostino. Roma: Pontificia Universidad Lateranense, 1969.

Svoboda, Karel. La estética de san Agustín y sus fuentes. Madrid: Augustinus, 1958.

Uña Juárez, Agustín. Cántico del universo: la estética de San Agustín. Madrid: s.d.e., 2000. Aunque este libro no tiene datos de edición, es una colección de artículos previamente publicados.

Van Deusen, Nancy. «Medieval organologies: Augustine vs Cassiodore on the subject of musical instruments». En Augustine on music: an interdisciplinary collection of essays, editado por Richard R. la Croix, 53-96. New York: The Edwin Mellen Press, 1988.

. «Musica, De». En Diccionario de san Agustín: Agustín a través del tiempo. Allan D. Fitzgerald dir. Traducción de Constantino Ruíz-Garrido Cortés, 924-927. Burgos: Monte Carmelo, 2001.

. «Musica, ritmo». En Diccionario de san Agustín: Agustín a través del tiempo. Allan D. Fitzgerald dir. Traducción de Constantino Ruíz-Garrido Cortés, 927-931. Burgos: Monte Carmelo, 2001. 